\title{
The Diabetes TRACK (by NEHEP) Vs Bangladesh
}

\section{Abdul Kader Mohiuddin}

Secretary and Treasurer, Dr. M. Nasirullah Memorial Trust, Tejgaon, Dhaka, Bangladesh

*Corresponding author: Abdul Kader Mohiuddin Secretary and Treasurer, Dr. M. Nasirullah Memorial Trust, Tejgaon, Dhaka, Bangladesh Received date: December 18, 2019; Accepted date: December 30, 2019; Published date: January 20, 2020. Citation: Abdul Kader Mohiuddin, The Diabetes TRACK (by NEHEP) Vs Bangladesh, J Diabetes and Islet Biology 3(1) Doi: 10.31579/2641- 8975/016

Copyright: (02020 Abdul K Mohiuddin this is an open-access article distributed under the terms of the Creative Commons Attribution License, which permits unrestricted use, distribution, and reproduction in any medium, provided the original author and source are credited.

\section{Abstract}

With the increasing burden of non-communicable diseases in low-income and middle-income countries (LMICs), biological risk factors, such as hyperglycemia, are a major public health concern in Bangladesh. Optimization of diabetes management by positive lifestyle changes is urgently required for prevention of comorbidities and complications, which in turn will reduce the cost. Diabetes had 2 times more days of inpatient treatment, 1.3 times more outpatient visits, and nearly 10 times more medications than non- diabetes patients, as reported by British Medical Journal. And surprisingly, $80 \%$ of people with this so called "Rich Man's Disease" live in low- and middle-income countries. According to a recent study of American Medical Association, China and India collectively are home of nearly 110 million diabetic patients. The prevalence of diabetes in this region is projected to increase by $71 \%$ by 2035 . Bangladesh was ranked as the 8 th highest diabetic populous country in the time period of 2010 2011. In Bangladesh, the estimated prevalence of diabetes among adults was $9.7 \%$ in 2011 and the number is projected to be 13.7 million by 2045 . The cost of diabetes care is considerably high in Bangladesh, and it is primarily driven by the medicine and hospitalization costs. According to Bangladesh Bureau of Statistics, in 2017 the annual average cost per T2DM was \$864.7, which is 52\% of per capita GDP of Bangladesh and 9.8 times higher than the general health care cost. Medicine is the highest source of direct cost (around 85\%) for patients without hospitalization. The private and public financing of diabetes treatment will be severely constrained in near future, representing a health threat for the Bangladeshi population.

Keywords: chronic diseases, hospitalization, T2DM

\section{Background}

Bangladesh is among the top 10 countries with the highest rates of projected age-standardized mortality among selected LMICs due to chronic diseases, particularly for CVDs and diabetes [1]. The age adjusted death rate 40 per 100,000 of population ranks Bangladesh 57 in the world, says WHO [2]. Diabetes is one of the four major types of noncommunicable diseases that make the largest contribution to morbidity and mortality worldwide. The International Diabetes Federation (IDF) estimated that, worldwide, approximately 425 million people had diabetes in 2017, projected to be 629 million by 2045. Again, worldwide $\$ 727$ billion was spent in 2017 for treating and preventing diabetes, projected to be US\$776 billion by 2045 [2]. In Bangladesh, specifically, the IDF projects the prevalence of diabetes will increase to more than $50 \%$ in the next 15years [4]. About 129,000 deaths were attributed to diabetes in Bangladesh in 2015, as reported by leading research organization ICDDR, B [5]. According to the WHO-Diabetes country profile of Bangladesh in 2016, the physical inactivity was prevailing among $25.1 \%$ of population [6]. Around $85 \%$ population of age group 25-65 never checks for diabetes [7]. A recent study by British Medical Journal says, 1 in 10 Bangladeshi adults aged $\geq 18$ years have hyperglycemia (among urban residents) [4]. Even in rural Bangladeshi community, undiagnosed diabetes was high, 7.2\% found in a 2016 [8] and $10 \%$ in 2019. 20-30\% of adults in rural areas of Bangladesh have abnormal fasting glucose or impaired glucose tolerance [9]. And IDF says, there are 7.1 million people with undetected diabetes in Bangladesh and this number will be double by 2025 [10]. Das et.al, 2019 reported prevalence of dyslipidemia was over $70 \%$ to both male and female subjects, which indicates the urgency of lifestyle intervention strategies to prevent and manage this important health problem and risk factor [11]. Among 8400 stroke patients from different hospitals in Bangladesh over a period of sixteen years, diabetic patients were nearly $25 \%$ [12]. Prevention strategies should focus on increasing physical activity, weight loss, smoking cessation, and more strict control of hypertension and glycemic level [13].

\section{TRACK Vs Bangladesh: Perplexity of the Present Situation}

\section{A. Compliance Issue}

Poor adherence is a well-documented obstacle in therapeutic control of diabetes. For an effective control and prevention of diabetes, $87 \%$ of Bangladeshis were noncompliant, compared to $71 \%$ of Indians and 52\% Europeans [16]. Out-of-pocket expenditure, emotional status, frequency of counseling, patient's family priorities, availability of medication (mainly insulin) are the factors greatly influence patient compliance to treatment guidelines. In 2016, the median monthly cost of diabetes maintenance was close to $\$ 10$, approximately $10 \%$ of the median monthly income [17]. According to a $2018 \mathrm{BBC}$ record, insulin availability found supplies were low in six countries - Bangladesh, Brazil, Malawi, Nepal, Pakistan and Sri Lanka [18]. Also, huge gap between the number of diabetic patients and doctors are well-known. The Diabetic Association of Bangladesh (DAB) record shows, except Dhaka and Chittagong, there are no tertiary facilities in Bangladesh to preventing blindness due to diabetic retinopathy [19]. 


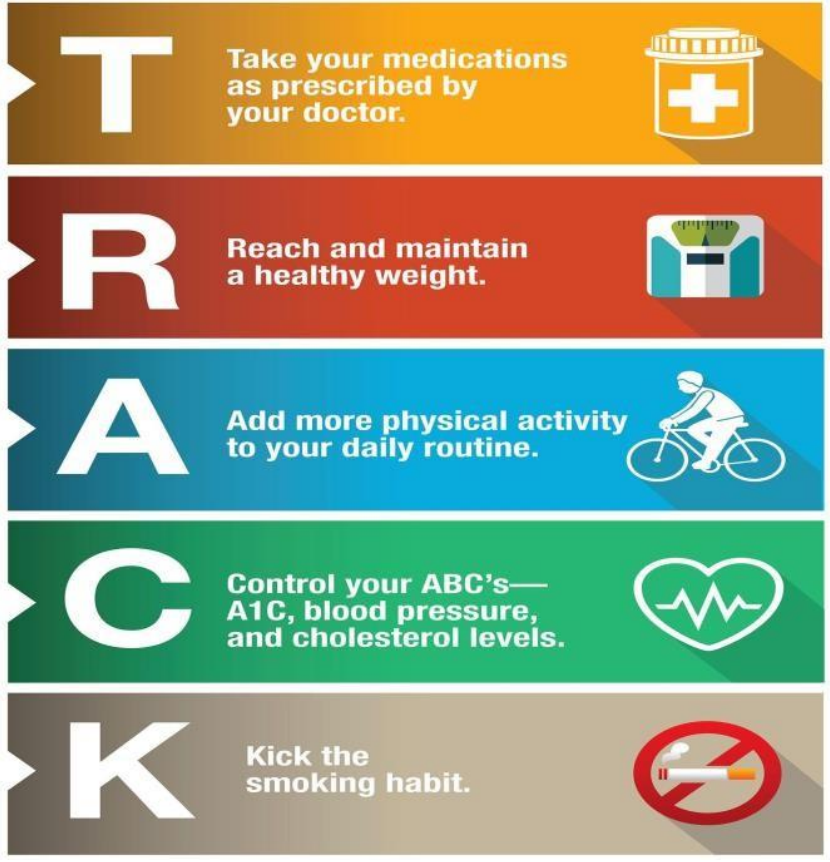

Figure 1. TRACK, A program of National Institute of Health (NIH), England to memorize the factors that can contribute to health while living with diabetes [14].

\section{B. Overweight Issue}

Overweight or obese children have a higher risk of becoming obese in adulthood and are at higher risk of associated chronic diseases [20]. Al Muktadir et.al, 2019 revealed that around 22\% to 27\% Bangladeshi youth were recorded as obese with different stages of obesity [21]. Another study says nearly $40 \%$ Bangladeshi youth, taking fast foods were recognized as overweight where $32 \%$ were noted as obese with different phases of obesity and overall prevalence of fast food consumption was about 53.8\% [22]. In a newspaper interview, Professor AK Azad Khan, President, Diabetic Association of Bangladesh said 40\% school going children of Dhaka city were either obese or overweight [23]. "Children with type 2 diabetes is rising "alarmingly" in Bangladesh. A 300\% raise in the last five years", according to the Changing Diabetes in Children Program of the BIRDEM hospital [24]. A community level study shows $35 \%$ of mothers perceived that childhood overweight/obesity could be a health problem and nearly $70 \%$ were not aware of any health consequences of childhood obesity [25]. Another study shows 97.4\% students consume fast food contain Monosodium Glutamate which causes obesity and other body discomforts [26]. In a similar study among students of 4 private universities of Dhaka, $98 \%$ of the students were well informed about the negative effects associated with excessive fast food consumption, they were still profoundly addicted to it [27]. Prevalence rates of overweight and obesity are higher in urban peoples compared to rural peoples living in Bangladesh [28]. Tanwi et.al, 2019 reported prevalence of overweight and obesity was 34\% among urban Bangladeshi women [29], increased by $17.5 \%$ between 1996 and 2011 [30]. Another study reveals that a nearly $30 \%$ married women in Bangladesh are overweight [31]. Women's employment status was only associated with overweight or obesity for urban residents. Working urban women had a lower probability of being overweight. Sociodemographic factors including age, education, wealth index, marital status, watching TV and employment status were associated with the increased trend of overweight and obesity [32]. The highest prevalence of overweight and obesity were observed in those women with the highest education level and wealth, larger family size, living in urban areas and not being in paid employment [33].

\section{Lifestyle Issues}

According to the WHO-Diabetes country profile of Bangladesh in 2016, the physical inactivity was prevailing more than $25 \%$ of population. Bangladeshi women more at health risk than men due to inactivity. Two big reason to diabetes among Bangladeshi people are carbohydratedependent food pattern and sedentary lifestyle [34-36]. While males can go outside, socialize and take part in outdoor activities such as cricket or football or cycling, females are often confined to domestic chores and not allowed to go outside freely. Parents are likely to restrict or discourage their daughters from outdoor activities such as recreational walking or bicycling. Young females are vulnerable to crime while travelling and so are more likely to avoid walking. Uddin et.al, 2019 reported that 80\% young adults in Dhaka City, did not meet the WHO recommended level of physical activity (150 minutes of moderate- to vigorous-intensity activity per week) for optimal health, with higher rates of insufficient activity among females than males [37]. unplanned urbanization in the cities where people have very limited scope for physical activities. Even in the rural areas people now take rickshaw vans or other rides to go to marketplaces. Evidence shows that prevalence of physical inactivity $35 \%$ to $38 \%$ in Bangladeshi adults aged 25 years and older [38]. Adults engage in high levels of sedentary behavior during waking hours, said another study [39]. Prevalence of self-reported depression was respectively $47.7 \%$ in Bangladesh. Lower frequency of vigorous physical activity was significantly associated with higher rates of depression diagnosed [40]. People with depressive disorders have a $65 \%$ greater risk of developing diabetes than the general population, which is a double-trouble according to WHO [41].

\section{Regular Health Checkup}

Despite the high levels of diabetes and intermediate hyperglycemia, awareness and control of the condition is low in rural Bangladesh. Fottrell et.al, 2019 reported only $25 \%$ of diabetics were aware of their status, women with diabetes were $37 \%$ less likely than men to know that they were diabetic and, even among known diabetics, $75 \%$ had suboptimal control of the condition [42]. It is mentioned earlier that 1 in 10 Bangladeshi urban adult (aged $\geq 18$ years) have hyperglycemia, with dyslipidemia prevalent over $70 \%$ male and females. Among those aged over 35, the Bangladesh Demographic and Health Survey (BDHS) reported that approximately $25 \%$ had abnormal fasting glucose [43]. The glycated hemoglobin (HbAlc) method does not require the candidate to fast for eight hours or take glucose and he or she can have the test done by the $\mathrm{HbA1c}$ method any time [44]. However, for individuals diagnosed with diabetes, screening is associated with a reduction in mortality and cardiovascular disease risk [45].

\section{E. Tobacco Smocking}

Tobacco kills more than seven million people a year worldwide and responsible for 1 in 5 deaths in Bangladesh, according to WHO, kills more than 161,000 people on average every year [46]. A number of experimental and clinical studies suggest that smoking decreases insulin sensitivity, and indirectly role plays in elevated blood sugar and LDL, decreased HDL and postprandial lipid intolerance [47-55]. A 2018 survey by BRAC University shows several risk factors of diabetes includes smoking (almost 60\%), abdominal obesity (43.3\%), hypertension $(14.3 \%)$, depression $(43 \%)$ whereas the incidence of routine bodily 
exercise (only $1.3 \%$ ) and the habit of consuming seasonal fruits as well as vegetables $(8.6 \%)$ remain significantly low among the people of Bangladesh [56]. Bangladesh has been identified as a high-achieving country for several tobacco control measures, including tobacco taxation, health warning labels and anti-tobacco mass-media campaigns. The high level of achievement for Bangladesh in cigarette taxation is, however, contradicted by an increase in per capita cigarette consumption [57]. Urban male smokers in Bangladesh consume more cigarettes than bidis and smoke more per day than rural smokers. More than half of Bangladeshi men over the age of 25 years smoke cigarettes or bidis, small handmade cigarettes containing about one fourth the amount of tobacco found in cigarettes [58]. Despite the reduction in overall tobacco use, the male smoking prevalence in Bangladesh is still high at 37\% [59]. Although, government is taking initiatives from administration, more than one fourth $(25.5 \%)$ of the police personnel in Bangladesh are currently smokers and this should be intervened [60].

\section{F. Other Issues}

Not only food and lifestyle, global warming also plays an important role in diabetes prevalence. A Netherlands based study in CNN Health says, "a 1-degree Celsius rise in environmental temperature could account for more than 100,000 new diabetes cases per year in the USA alone" [18]. A similar study says Bangladesh will exceed 35-degree Celsius before the end of the century [61]. Consuming arsenic contaminated food grains could be another reason of high diabetes prevalence [62]. Again, $15 \%$ of expecting women are diagnosed with gestational among these $60 \%$ contribute to permanent diabetes within 10 years, says Dr Samsad Jahan (professor of Obstetrics and Gynecology, BIRDEM) [63].

Fasting during Ramadan is significantly associated with decrease in blood lipid profile, blood pressures, glucose, and $\mathrm{HbA} 1 \mathrm{C}$ level among diabetic patients [64-70]. The total energy intake decreases during Ramadan, whereas the dietary fat consumption increases because of an augmentation of fatty food that does not occur during other periods [71]. Even more unfortunate is the fact that nefarious practice food adulteration increases exponentially during the month of Ramadan in Bangladesh, according to a study of European Journal of Sustainable Development Research, 2019 [72]. The number of patients suffering from cancer, diabetes, and kidney diseases is on the rise due to food adulteration [7376].

\section{Conclusion}

The prevalence of type 2 diabetes showed an increasing trend in both urban and rural population in Bangladesh. People with no education, lower socio-economic status, and those who lived in disadvantaged regions in terms of education and economic profile were found lacking of diagnosis, treatment, and control of diabetes. Children with diabetes are still managed by adult physicians or occasionally by adult diabetologists, except in institutions like BIRDEM, and Dhaka Shishu Hospital. Children and adolescents have special needs at different stages e.g., nutrition, schooling, growth, puberty etc. Improving detection, awareness, and treatment strategies is urgently needed to prevent the growing burden associated with diabetes. Emphasizing medication adherence with multiple comorbid diseases should be strongly considered in future diabetes management programs to improve glycemic control in patients with type 2 diabetes. The most important thing is patient education, that the modern world is giving the highest priorities. Rich or poor, privileged or unprivileged, all segment of population should be brought under the arena of compliance through patient education, at least by health campaign. Both government and profit taking medicine companies should take initiatives in this regard.

\section{Acknowledgment}

I'm thankful to Dr. Afsana Afroz, Department of Epidemiology and Preventive Medicine, School of Public Health and Preventive Medicine, Monash University, Melbourne, Australia for her valuable time to audit my paper and for her thoughtful suggestions. I'm also grateful to seminar library of Faculty of Pharmacy, University of Dhaka and BANSDOC Library, Bangladesh for providing me books, journal and newsletters.

\section{Abbreviations}

Low- and middle-income countries (LMICs); International Diabetes Federation (IDF); National Eye Health Education Program (NEHEP); Bangladesh Demographic and Health Survey (BDHS); Bangladesh Institute of Research and Rehabilitation in Diabetes, Endocrine and Metabolic Disorders (BIRDEM)

\section{References}

1. Ali, Nausad (2019)“Sex-specific prevalence, inequality and associated predictors of hypertension, diabetes, and comorbidity among Bangladeshi adults: results from a nationwide cross-sectional demographic and health survey." 17;9(9).

2. Mohiuddin AK. (2019) Diabetes Fact: Bangladesh Perspective. International Journal of Diabetes Research; 2(1): 14-20.

3. Afroz Afsana, Khurshid Alam, Liaquat Ali, Afsana Karim, Mohammed J. Alramadan et al. (2019)“Type 2 diabetes mellitus in Bangladesh: a prevalence based cost-of-illness study." BMC health services research 19(1)60.

4. Islam, Jessica Yasmine, Mohammad Mostafa Zaman1, Mahfuz Rahman Bhuiyan1, Syed Atiqul Haq et al. (2019) "Prevalence and determinants of hyperglycaemia among adults in Bangladesh: results from a population-based national survey."

5. Salahuddin T. (2019) The rising threat of NCDs in Bangladesh. The Daily Star, January 06.

6. Salahuddin T. (2018) Obesity is increasing among the younger generation in Bangladesh. The Daily Star, September 23.

7. Star Online Report. 80 lakh Bangladeshis suffering from diabetes: State minister. The Daily Star, April 06, 2016.

8. Islam FM, Chakrabarti R, Islam MT, Wahab M, Lamoureux E et al(2016) Prediabetes, diagnosed and undiagnosed diabetes, their risk factors and association with knowledge of diabetes in rural Bangladesh: The Bangladesh Population-based Diabetes and Eye Study. J Diabetes.;8(2):260-268.

9. Fottrell, Edward,Naveed Ahmed, Joanna Morrison,Abdul Kuddus,Sanjit Kumer Shaha et al. (2019) "Community groups or mobile phone messaging to prevent and control type 2 diabetes and intermediate hyperglycaemia in Bangladesh (DMagic): a cluster-randomised controlled trial." The lancet. Diabetes \& endocrinology vol. 7(3): 200-212.

10. Shariful Islam, Sheikh Mohammed Lechner, Ferrari, Laxy , Seissle, et al. (2017)"Healthcare use and expenditure for diabetes in Bangladesh." BMJ global health vol. 2(1).

11. Das H, Banik S. (2019).Prevalence of dyslipidemia among the diabetic patients in southern Bangladesh: A cross-sectional study. Diabetes Metab Syndr. 13(1):252-257.

12. Mohammad QD, Habib M, Mondal BA, Chowdhury RN, Hasan MH, et al (2014)Stroke in Bangladeshi patients and risk factor. Mymensingh Med J. Jul;23(3):520-529. 
13. Afroz A, Zhang W, Wei Loh AJ, Jie Lee DX, Billah B.(2019) Macro- and micro-vascular complications and their determinants among people with type 2 diabetes in Bangladesh. Diabetes Metab Syndr;13(5):2939-2946.

14. National Institute of Health (UK). Stay on TRACK To Prevent Blindness From Diabetes.

15. American Association of Diabetes Educators. Resources for People Living with Diabetes (Monitoring).

16. Mohiuddin AK.( (2018)). Domination of Nephrotic Problems among Diabetic Patients of Bangladesh. Archives of Nephrology and Urology 1: 009-016.

17. Vanderlee L, Ahmed S, Ferdous F, Farzana FD, Das SK et al(2016) Self-care practices and barriers to compliance among patients with diabetes in a community in rural Bangladesh. Int J Diabetes Dev Ctries; 36: 320.

18. Azad A.(2018) How climate change will affect your health. CNN health, October 12,

19. Diabetic Association of Bangladesh. WDF-494 Extension of Diabetic Retinopathy Care in Bangladesh.

20. Alam MM, Hawlader MDH, Wahab A, Hossain MD, Nishat SA, et al (2019)Determinants of overweight and obesity among urban school-going children and adolescents: a case-control study in Bangladesh. Int J Adolesc Med Health. May 9.

21. Al Muktadir MH, Islam MA, Amin MN, Ghosh S, Siddiqui SA et al(2019). Nutrition transition - Pattern IV: Leads Bangladeshi youth to the increasing prevalence of overweight and obesity. Diabetes Metab Syndr. May - Jun;13(3):1943-1947.

22. Goon S, Bipasha MS, Islam S.(2014) Fast food consumption and obesity risk among university students of Bangladesh. Eur J Prev Med;2:99e104.

23. World Diabetes Day 2018. "Access to insulin is a human right" In conversation with Professor AK Azad Khan, President, Diabetic Association of Bangladesh. The Daily Star, November $14,2018$.

24. Hasib NI. (2016).Children getting type 2 diabetes 'alarmingly' in Bangladesh. bdnews24.com 06 April.

25. Hossain MS, Siddiqee MH, Ferdous S, Faruki M, Jahan R, et al (2019).Is Childhood Overweight/Obesity Perceived as a Health Problem by Mothers of Preschool Aged Children in Bangladesh? A Community Level Cross-Sectional Study. Int J Environ Res Public Health.

26. Chaity AJ.(2017) Obesity blamed for alarming rise in childhood diabetes DhakaTribune November $13^{\text {th }}$.

27. Bipasha M, Goon S.(2014)Fast food preferences and food habits among students of private universities in Bangladesh. South East Asia Journal of Public Health; 3(1): 61-64.

28. Tanwi, Tania Sultana (2019) "Socioeconomic correlates of overweight and obesity among ever-married urban women in Bangladesh.” BMC public health 19(1) 842.

29. Hoque ME, Long KZ, Niessen LW, Al Mamun A. (2015) Rapid shift toward overweight from double burden of underweight and overweight among Bangladeshi women: a systematic review and pooled analysis. Nutr Rev. 73(7):47-438.

30. Banik S, Rahman M. (2018) Prevalence of Overweight and Obesity in Bangladesh: a Systematic Review of the Literature. Curr Obes Rep.7(4):247-253.

31. Biswas, Tuhin (2017) "The prevalence of underweight, overweight and obesity in Bangladeshi adults: Data from a national survey." PloS one vol. 12(5).

32. Chowdhury, Muhammad Abdul Baker (2018) "Trends, prevalence and risk factors of overweight and obesity among women of reproductive age in Bangladesh: a pooled analysis of five national cross-sectional surveys." $8(7)$.
33. Biswas T, Uddin MJ, Mamun AA, Pervin S, P Garnett S.( 2017) Increasing prevalence of overweight and obesity in Bangladeshi women of reproductive age: Findings from 2004 to 2014. 28;12(7).

34. Guthold R, Stevens GA, Riley LM, Bull FC.( 2018) Worldwide trends in insufficient physical activity from 2001 to 2016: a pooled analysis of 358 population-based surveys with 1.9 million participants. Lancet Glob Health. 6(10).

35. Mahbub I. Why Is Diabetes on The Rise in Bangladesh? Web Future Startup October 25, 2016.

36. Tareq S.(2018) Obesity is increasing among the younger generation in Bangladesh The Daily Star September 23.

37. Uddin, Riaz (2017)"Prevalence and sociodemographic patterns of physical activity among Bangladeshi young adults." Journal of health, population, and nutrition 36(1).

38. Moniruzzaman, Mohammad "Physical activity levels and associated socio-demographic factors in Bangladeshi adults: a cross-sectional study." BMC public health vol. 17(1) 59.

39. Vancampfort D, Firth J, Schuch F, Rosenbaum S, De Hert M, et al (2016)Physical activity and sedentary behavior in people with bipolar disorder: A systematic review and meta-analysis. J Affect Disord. Sep 1;201:145-52.

40. Bishwajit, Ghose ,O'Leary, Ghosh, Yaya, Shangfeng et al. (2017)"Physical inactivity and self-reported depression among middle- and older-aged population in South Asia: World health survey." BMC geriatrics vol. 17(1).

41. WHO Bangladesh. Double trouble: diabetes and depression.

42. Fottrell, Edward, Naveed Ahmed, Sanjit Kumar Shaha, Hannah Jennings, Abdul Kuddus et al. (2018)"Diabetes knowledge and care practices among adults in rural Bangladesh: a crosssectional survey." BMJ global health 3(4) 23.

43. Fottrell, Edward, Naveed Ahmed, Sanjit Kumer Shaha, Hannah Jennings et al.( 2018) "Distribution of diabetes, hypertension and non-communicable disease risk factors among adults in rural Bangladesh: a cross-sectional survey." BMJ global health vol. 3(6).

44. Palma P. (2018). A worrying picture of diabetes in Bangladesh. The Daily Star, November 14,.

45. Health Tips. Screening reduces mortality for detectable type 2 diabetics. The Daily Star, August 27, 2017.

46. Hasan MK.( 2018)WHO: Tobacco responsible for 1 in 5 deaths in Bangladesh. DhakaTribune, June 01.

47. Bergman, Bryan $\mathrm{C}$ "Novel and reversible mechanisms of smoking-induced insulin resistance in humans." Diabetes vol. 61,12 (2012): 3156-66.

48. Kong C, Nimmo L, Elatrozy T, Anyaoku V, Hughes C et al. (2001) Smoking is associated with increased hepatic lipase activity, insulin resistance, dyslipidaemia and early atherosclerosis in Type 2 diabetes. Atherosclerosis. Jun;156(2):373-378.

49. Schofield, Jonathan D et al.( 2016) "Diabetes Dyslipidemia." Diabetes therapy : research, treatment and education of diabetes and related disorders vol. 7(2) 203-219.

50. Facchini FS, Hollenbeck CB, Jeppesen J, Chen YD, Reaven GM.( 1992 ). Insulin resistance and cigarette smoking. Lancet. May 9;339(8802):1128-11230.

51. Bajaj, Mandeep. (2012) "Nicotine and insulin resistance: when the smoke clears." Diabetes vol. 61(12)

52. Harris, Kindred K (2016) "Metabolic effects of smoking cessation." Nature reviews. Endocrinology vol. 12,5: 299-308.

53. Calcaterra V, Winickoff JP, Klersy C, Schiano LM, Bazzano R et al (2018)Smoke exposure and cardio-metabolic profile in youth with type 1 diabetes. Diabetol Metab Syndr. 6;10:53. 
54. Rao Ch, Srinivasa, and Emmanuel Subash Y. (2013): "The effect of chronic tobacco smoking and chewing on the lipid profile." Journal of clinical and diagnostic research : JCDR vol. 7(1) 31-34.

55. Gossett, Linda K,Johnson HM, Piper ME, Fiore MC, Baker TB, et al.(2009) "Smoking intensity and lipoprotein abnormalities in active smokers." Journal of clinical lipidology vol. 3,6: 372378.

56. Wasifuzzaman C. A review of prevalence, complications, risk factors, knowledge assessment, self-management, consciousness and treatment of diabetes mellitus in Bangladesh.

57. Nargis, Nigar (2019): “A decade of cigarette taxation in Bangladesh: lessons learnt for tobacco control." Bulletin of the World Health Organization vol. 97(3)221-229.

58. Alam, Dewan S (2013 )"Smoking-attributable mortality in Bangladesh: proportional mortality study." Bulletin of the World Health Organization vol. 91(10): 757-764.

59. Nargis, Nigar, Thompson ME, Fong GT, Driezen P, Hussain AK et al. (2015) "Prevalence and Patterns of Tobacco Use in Bangladesh from 2009 to 2012: Evidence from International Tobacco Control (ITC) Study.” 10(11).

60. Khan MK, Hoque HE, Ferdous J.( 2019). Knowledge and Attitude Regarding National Tobacco Control Law and Practice of Tobacco Smoking among Bangladesh Police. Mymensingh Med J. Oct;28(4):752-761.

61. Tribune Desk.(2017) Temperature in Bangladesh to rise to deadly heights by end of century. DhakaTribune, August 03.

62. Mohiuddin AK.( 2019) Domination of Pollutant Residues among Food Products of South-East Asian Countries. South Asian Res J Agri Fish; Vol-1(2) 50-53.

63. Chaity AJ. $15 \%$ pregnant women diagnosed with diabetes. DhakaTribune, November 14, 2017.

64. Bener A, Yousafzai MT.(2014) Effect of Ramadan fasting on diabetes mellitus: a population-based study in Qatar. J Egypt Public Health Assoc. Aug;89(2):47-52.

65. Yeoh EC, Zainudin SB, Loh WN, Chua CL, Fun S ,et al .(2015) Fasting during Ramadan and Associated Changes in Glycaemia, Caloric Intake and Body Composition with Gender
Differences in Singapore. Ann Acad Med Singapore. Jun;44(6):202-206.

66. Bener, Abdülbari (2018) "Effect of ramadan fasting on glycemic control and other essential variables in diabetic patients." Annals of African medicine 17(4) 196-202.

67. Bener A, A Al-Hamaq AOA, Öztürk M, Çatan F, Haris PI, et al (2018). Effect of ramadan fasting on glycemic control and other essential variables in diabetic patients. Ann Afr Med. 17(4):196-202.

68. Ahmed, Mohamed H (2017) "Diabetes and Ramadan: A concise and practical update." Journal of family medicine and primary care vol. 6(1): 11-18.

69. Malinowski, Bartosz (2019) “Intermittent Fasting in Cardiovascular Disorders-An Overview." Nutrients vol. 11(3) 673.

70. Siaw, Melanie Y L, Chew DE, Toh MP, Seah DE, et al. (2016) "Metabolic parameters in type 2 diabetic patients with varying degrees of glycemic control during Ramadan: An observational study." Journal of diabetes investigation vol. 7(1) 70-75.

71. Khaled, Boumédiène Méghit, and Slimane Belbraouet.(2009)"Effect of Ramadan fasting on anthropometric parameters and food consumption in 276 type 2 diabetic obese women." International journal of diabetes in developing countries vol. 29 (2) 62-68.

72. Mohiuddin, A. K. (2019). Chemical Contaminants and Pollutants in the Measurable Life of Dhaka City. European Journal of Sustainable Development Research, 3(2), em0083.

73. Ullah A.(2019) Sale of Adulterated Spice Powder: Public health at risk. The Daily Sun, October 16.

74. Staff Correspondent.(2011)Food adulteration rings alarm bell: STAR-RDRS roundtable told most food items adulterated, pose lethal risks to public health. The Daily Star, August 11.

75. Majed N, Real MIH, Akter Mand Azam HM (2016) Food Adulteration and Bio-Magnification of Environmental Contaminants: A Comprehensive Risk Framework for Bangladesh. Front.Environ.Sci.4:34.

76. Chowdhury MFI.(2014) Evaluating Position of Bangladesh to Combat 'Adulterated Food' Crisis in Light of Human Rights. OSR Journal Of Humanities And Social Science (IOSR-JHSS) 19 (3), Ver. VI (Mar.), PP 45-54. 